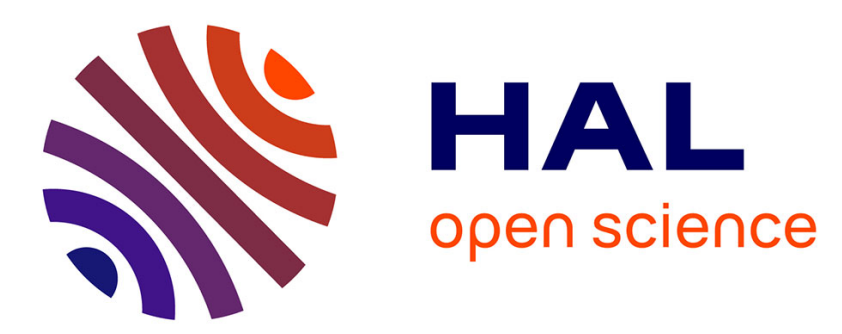

\title{
Multi-star multi-phase winding for a high power naval propulsion machine with low ripple torques and high fault tolerant ability
}

Franck Scuiller, Jean-Frederic Charpentier, Eric Semail

\section{To cite this version:}

Franck Scuiller, Jean-Frederic Charpentier, Eric Semail. Multi-star multi-phase winding for a high power naval propulsion machine with low ripple torques and high fault tolerant ability. VPPC'10, IEEE International Vehicular Power Propulsion Conference, Sep 2010, France. pp.1-5, 10.1109/VPPC.2010.5729185 . hal-00819007

\section{HAL Id: hal-00819007 https://hal.science/hal-00819007}

Submitted on 29 Apr 2013

HAL is a multi-disciplinary open access archive for the deposit and dissemination of scientific research documents, whether they are published or not. The documents may come from teaching and research institutions in France or abroad, or from public or private research centers.
L'archive ouverte pluridisciplinaire $\mathbf{H A L}$, est destinée au dépôt et à la diffusion de documents scientifiques de niveau recherche, publiés ou non, émanant des établissements d'enseignement et de recherche français ou étrangers, des laboratoires publics ou privés. 


\title{
Multi-star multi-phase winding for a high power naval propulsion machine with low ripple torques and high fault tolerant ability.
}

\author{
Franck Scuiller, Jean-Frédéric Charpentier Institut de Recherche de l'Ecole Navale \\ F-29240 Brest-Armées, France \\ franck.scuiller@ecole-navale.fr \\ jean-frederic.charpentier@ecole-navale.fr Eric Semail Arts et Métiers ParisTech, F-59000 Lille, France \\ Université Lille Nord de France, F-59000 Lille, France \\ eric.semail@ensam.eu
}

\begin{abstract}
In this paper, an original multi-phase Surface Mounted Permanent Magnet (SMPM) Machine designed for naval propulsion is proposed. The design objective of this high power low speed machine is twofold: to enhance the fault tolerance capability of the system and to optimize the quality of the torque by reducing the electromagnetic torque ripples which underlie the acoustic behaviour of the motor and of the global mechanical structure. A low level of ripple torques must also be ensured in faulty operations. To fullfill these constraints, the machine is equipped with a fractional-slot concentrated winding made up of four 3-phase windings each one being star-connected, each star being magnetically shifted by an angle of 15 degrees. This 4-star 3-phase configuration allows to reduce the cogging torque and to separate magnetically and physically the phase windings. The end-turns are also drastically reduced, which improves the compactness and the efficiency of the machine. This original multi-phase machine is supplied by four 3-phase PWM voltage source inverter with sinusoidal current law. The magnetic independences between the four star windings allow a very simple control of the four-star supply and a straightforward fault operating mode. Moreover, this 4-star winding configuration yields to very low torque ripples in nominal configuration (four stars connected) and in faulty operations if two magnetic non adjacent stars are disconnected. For all these reasons, this structure appears particularly suitable for naval propulsion application since it increases the machine performances in terms of compactness, reliability and quality of torque.
\end{abstract}

\section{INTRODUCTION}

In naval propulsion application, the main challenges are to increase the torque density of the electrical machine for minimization of mass and volume, and to improve the reliability of the system. To achieve this goal, the use of a multi-phase PM Synchronous Machine supplied by a Pulse Width Modulation VSI is probably one of the more advantageous solutions [1].

With this solution, a multi-phase motor in naval propulsion applications can also be very interesting to improve the quality of torque. With a high number of phases, it is possible to find a machine design and control strategies which minimize the pulsating torque and consequently improve the acoustic behaviour of the system [2]. The multiple-star winding also leads itself to the reduction of the pulsating torques [3], [4].

Besides, multiple-star configurations are also of high interest as their control under normal and fault modes can be straightforward: when one phase is opened, its corresponding star is no longer supplied. Unfortunately, in this faulty operation when one star is diconnected, the increase of the pulsating torques can be embarrassing especially at low speed. A 4-star system can overcome this effects if necessary: when one phase is opened, its corresponding star and the non adjacent star are no longer supplied, which allows to preserve a low level of ripple torques. In case of PWM VSI supply, this strategy could be efficient only if the magnetic couplings between the stars is weak. The 4-star 3-phase winding proposed in this paper is designed according to this objective.

\section{Multi-STAR MUlti-PHASE WINDING ANALYSIS}

Multi-star multi-phase windings are known for their ability to drastically reduce the pulsating torques. The stator with two 3-phase windings with a spatial shift angle of 30 degrees is probably the more common topology of multi-star multiphase systems [5]. The configuration leads to a machine which behaves as a 12-phase machine concerning pulsating torques. Concerning the drive design, this result is particularly interesting because only 6 phases are to be supplied to obtain the behaviour of a 12-phase machine. In this part, this result is generalized.

\section{A. Pulsating torque for a $N$-phase machine}

In this part, the electromagnetic torque of a N-phase machine is calculated. The $\mathrm{N}$-phase machine checks the following assumptions:

- (H1) the $N$ phases are identical

- (H2) the $N$ phases are regularly shifted

- (H3) $N$ is odd

- (H4) the phase back-electromotive force is perfectly antisymetric (no even harmonics in the back-electromotive force)

- (H5) the phase current is perfectly anti-symetric (no even harmonics in the current)

Hypothesis (H4) is satisfied from the machine design whereas hypothesis (H5) fullfillment mainly depends on the drive.

The electromagnetic torque is estimated by the following expression (where $\theta, \epsilon_{n}$ and $i_{n}$ respectively denote the rotor 
position, the back-EMF at $1 \mathrm{rad} / \mathrm{s}$ speed (called elementary back-emf in the paper) and the current for the phase $n$ ):

$$
T(\theta)=\sum_{n=0}^{N-1} \epsilon_{n}(\theta) i_{n}(\theta)
$$

Elementary back-emf and phase currents can be expanded into spatial Fourier series taking into account hypothesis (H1) and (H2):

$$
\left\{\begin{array}{l}
\epsilon_{n}(\theta)=\sum_{h=-\infty}^{+\infty} \widehat{\left(\epsilon_{n}\right)_{h}} e^{j h \theta}=\sum_{h=-\infty}^{+\infty} \widehat{\left(\epsilon_{0}\right)_{h}} e^{-j \frac{2 \pi}{N} h n} e^{j h \theta} \\
i_{n}(\theta)=\sum_{h=-\infty}^{+\infty} \widehat{\left(i_{n}\right)_{h}} e^{j h \theta}=\sum_{h=-\infty}^{+\infty} \widehat{\left(i_{0}\right)_{h}} e^{-j \frac{2 \pi}{N} h n} e^{j h \theta}
\end{array}\right.
$$

Relations (2) and (1) lead to the following expression for the electromagnetic torque of the N-phase machine:

$$
T(\theta)=\sum_{q=-\infty}^{+\infty}\left[N \sum_{h=-\infty}^{+\infty}{\widehat{\left(\epsilon_{0}\right)}}_{h}{\widehat{\left(i_{0}\right)}}_{q N-h}\right] e^{j q N \theta}
$$

If hypothesis (H3), (H4) and (H5) are considered, some harmonics are cancelled in relation (3). The following expression for the electromagnetic torques appears:

$$
T(\theta)=\sum_{q=-\infty}^{+\infty}\left[N \sum_{h=-\infty}^{+\infty}{\widehat{\left(\epsilon_{0}\right)}}_{h}{\widehat{\left(i 0_{0}\right)}}_{2 q N-h}\right] e^{j 2 q N \theta}
$$

For a N-phase machine that checks hypothesis (H1) to (H5), the spatial pulsating torque periodicity is $\pi / N$.

\section{B. Pulsating torque for a $S$-star $N$-phase machine}

In this part, the stator winding is supposed made with $S$ elementary $\mathrm{N}$-phase windings, each $\mathrm{N}$-phase winding shifted with the particular spatial angle $2 \pi /(2 S N)$. The total electromagnetic torque is the sum of the torque resulted from each $\mathrm{N}$-phase winding. Considering relation (4), the following expression comes:

$$
\begin{aligned}
& T(\theta)=\sum_{s=0}^{S-1} T_{s}(\theta) \\
& =\sum_{s=0}^{S-1} \sum_{q=-\infty}^{+\infty}\left[N \sum_{h=-\infty}^{+\infty}{\widehat{\left(\epsilon_{0}\right)}}_{h}{\widehat{\left(i_{0}\right)}}_{2 q N-h}\right] e^{j 2 q N\left(\theta-s \frac{2 \pi}{2 S N}\right)}
\end{aligned}
$$

The total electromagnetic torque becomes:

$$
T(\theta)=N S \sum_{k=-\infty}^{+\infty}\left[\sum_{h=-\infty}^{+\infty}{\widehat{\left(\epsilon_{0}\right)}}_{h} \widehat{(i)}_{2 k S N-h}\right] e^{j 2 k S N \theta}
$$

According to relation (6), the spatial periodicity of the pulsating torque generated by the $\mathrm{S}$-star $\mathrm{N}$-phase machine is $\pi /(S N)$. For the example of the 2-star 3-phase asymmetrical machine, the first harmonic of the pulsating torque is 12 .

\section{NAVAL PROPULSION MACHINE DESIGN}

\section{A. Naval propeller specifications}

The naval propulsion machine studied in this paper must satisfy the following requirements:

- low level of torque ripples
TABLE I

PROPELLER CHARACTERISTICS

\begin{tabular}{|c|c|}
\hline Power @ speed & 5000kW @ 90rpm \\
\hline Effective length & $1 \mathrm{~m}$ \\
\hline Stator diameter $D$ & $2.84 \mathrm{~m}$ \\
\hline Stator yoke thickness & $0.03 \mathrm{~m}$ \\
\hline Mechanical airgap $g$ & $0.006 \mathrm{~m}$ \\
\hline Rotor yoke thickness & $0.03 \mathrm{~m}$ \\
\hline Magnet layer thickness & $0.016 \mathrm{~m}$ \\
\hline Magnet layer length to pole pitch & $2 / 3$ \\
\hline Remanent flux density $B_{r}$ & $1 \mathrm{~T}$ \\
\hline Slot width $\left(\tau_{s}\right.$, tooth pitch) & $0.45 \tau_{s}$ \\
\hline Slot width opening & $0.25 \tau_{s}$ \\
\hline Slot-closing thickness & $0.004 \mathrm{~m}$ \\
\hline Slot depth & $0.037 \mathrm{~m}$ \\
\hline Linear load $A$ & $5.910^{4} \mathrm{~A} / \mathrm{m}$ \\
\hline Current density $j_{s}$ & $4.010^{6} \mathrm{~A} / \mathrm{m}^{2}$ \\
\hline
\end{tabular}

- high level of compacity

- high fault tolerant ability with possibility to provide smooth torque at low speed in faulty conditions

- very simple control in fault mode operation by deconnexion of wye-coupled windings

These constraints lead to choose a multi-star multi-phase SMPM machine. Table I gives the main magnetic characteristics of the naval propulsion machine.

B. Choice of the phase and star numbers for the naval propulsion machine

The phase number $N$ is chosen to be 3 in order to split the machine power into a high number of stars. The star number $S$ is chosen to be 4 as shown by figure 1 -a. This number is particularly adapted to satisfy the constraint concerning the ability of the machine to provide a smooth torque in fault conditions. Indeed, as illustated by figure 1 - $b$, if the star number 1 is lost, the initial 4-star 3-phase machine can behave as a 2-star 3-phase if the star number 3 is disconnected. A low level of pulsating torque is then obtained.
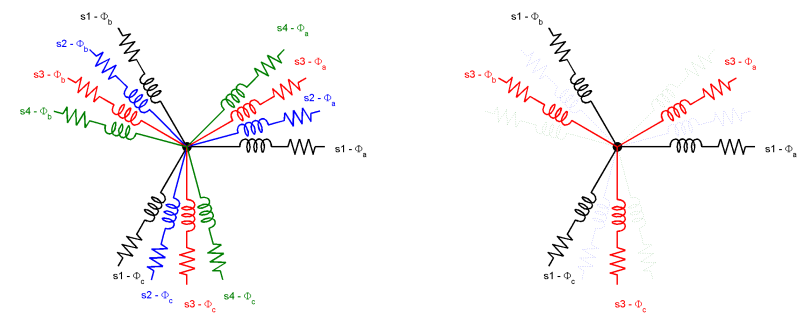

(a) Nominal configuration: $S=$ (b) Fault condition configuration to $4, N=3$ have smooth torque: $S=2, N=3$

Fig. 1. 4-star 3-phase winding scheme for the naval propulsion machine

\section{Fractional-slot concentrated winding}

A fractional-slot concentrated winding with one phase per slot is selected. This kind of winding weakens the cogging 
torque and allows a physical separation of the coils phases. This physical separation can be particularly advantageous in case of severe thermal damages of a phase winding. The fault tolerant ability is thus reinforced. Furthermore, the mutual inductance between the phases are reduced, which makes the machine control easier: algorithms dedicated to wye-coupled 3-phase machines can be used to control each of the 4 stars. Each star is supplied with a PWM voltage source inverter.

The winding distribution is calculated by using the modeling described in [6]. Pole pair number is chosen regarding the speed machine and the slot number is chosen in order to make possible the concentrated coils configrations: in this procedure, constraints regarding the iron core saturation are taken into account. Figure 2 gives a view of the electromagnetic parts of the machine: a three-phase winding (made with 12 coils, 4 coils per phase) is represented.

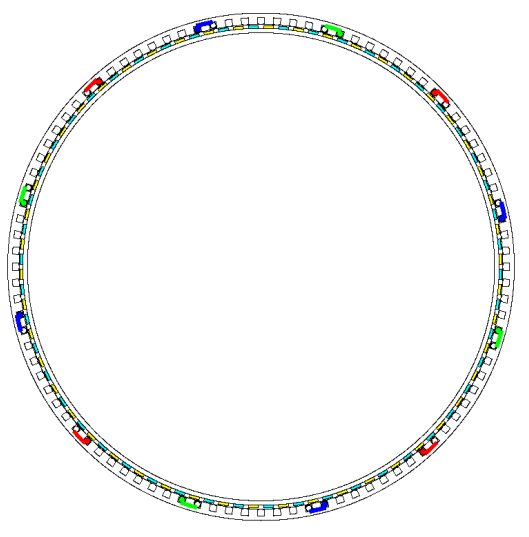

Fig. 2. Electromagnetic view of the machine

The physical separation of the coils phases is checked by using the numerical software Difimedi [7]. Figure 3 depicts the flux density patterns when one phase is supplied: this numerical estimations leads to a main inductance equal to $0.9 \mathrm{mH}$ whereas the higher mutual inductances only represents $3 \%$ of the main inductances.

The magnet layer is designed to cancel harmonic 3 in the back-emf. Figure 2 presents the electromagnetic aspect of the machine and figure 4 gives the back-emf waveform obtained from an analytical calculation. This analytical estimation is validated using the numerical software: no load flux density patterns are depicted in figure 5

\section{Simulation Results}

\section{A. Efficiency}

Figure 6 shows the efficiency of the naval propulsion machine with a load torque proportionnal to the squared speed (in order to simply model the propeller law) for maximum torque per ampere (MTPA) running. The switching and conduction losses are estimated from an analytical model described in [8]. It can be observed that the efficiency is upper than $80 \%$ for a speed higher than $8 \mathrm{rad} / \mathrm{s}$ when all the stars are connected.

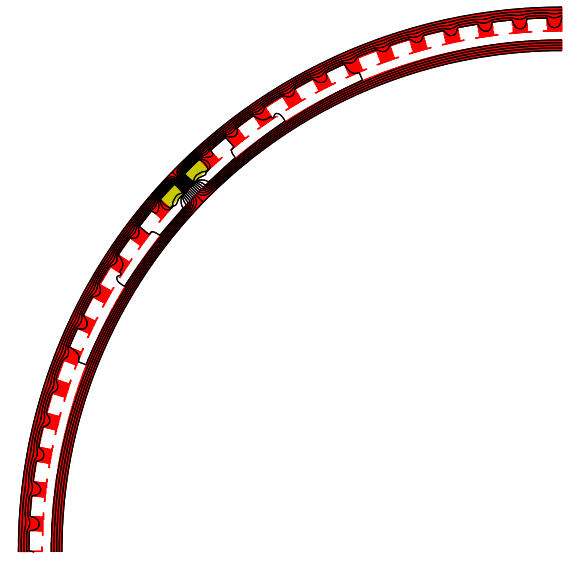

Fig. 3. Flux density patterns estimation when one phase is supplied

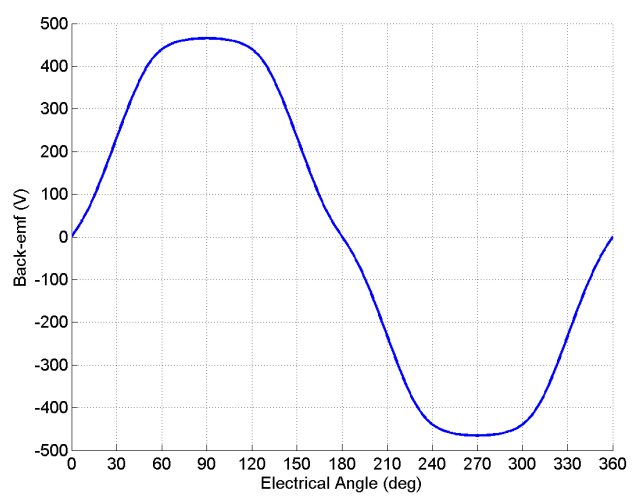

Fig. 4. Back-emf waveform of the machine

\section{B. Electromagnetic torque waveform}

Figure 7 gives the maximum electromagnetic torque produced by the machine in case of perfect sinusoidal currents: the very low level of pulsating torques is clear when the whole stars are connected and when stars 1 and 3 (or 2 and 4) are connected.

The PWM VSI effects are analysed by using Matlab/Simulink software. For this purpose, the switches are supposed to be perfect and a simple intersective modulation is simulated: the carrier frequency is equal to $5000 \mathrm{~Hz}$. This value is chosen by considering the machine electrical time constant and the voltage, current and power levels of the inverters. Figure 8 gives the simulated phase currents and figure 9 shows the corresponding electromagnetic torques: the expected low level of pulsating torque is confirmed. 


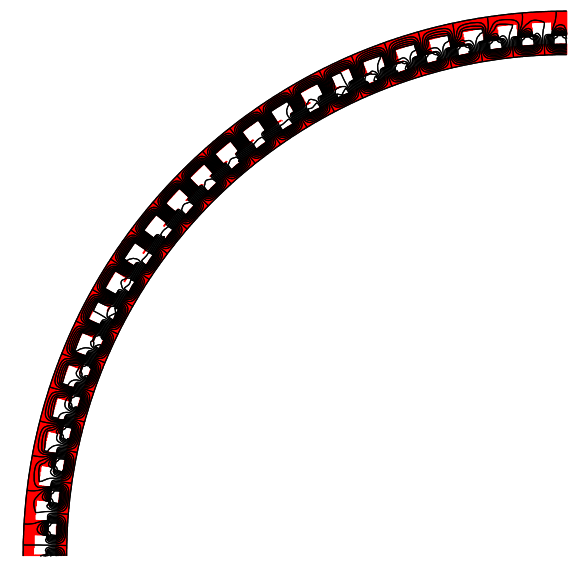

Fig. 5. No load flux density patterns

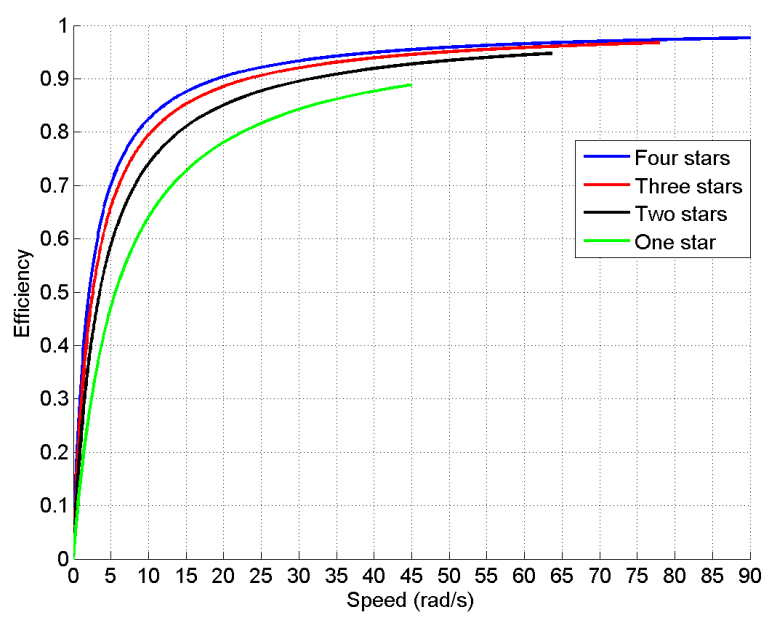

Fig. 6. Efficiency versus speed with the propeller law

Table III precises the pulsating torque magnitudes in the different configurations and allows to determine the influence of the PWM on the torque waveforms: it can be concluded that the PWM increases the pulsating torque by $5 \%$ referencing the mean torque. This high frequency torque will probably be filtered by the mechanical drive.

\section{CONClusion}

In this paper, the proposed 4-star 3-phase concentrated fractional-slot winding allows to minimize the pulsating torques and to benefit from efficient and simple fault operating modes. This original solution reduces the end-turns of the

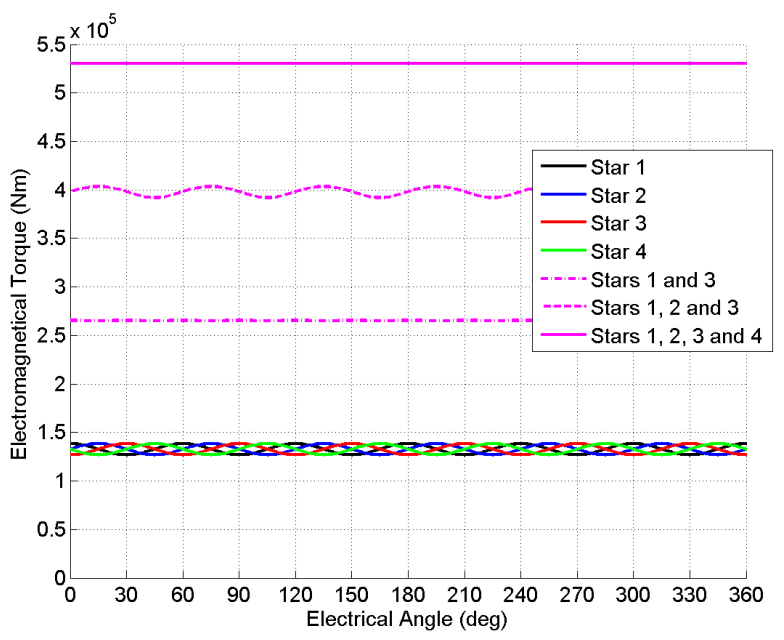

Fig. 7. Maximum electromagnetic torque with perfect sinusoidal current hypothesis

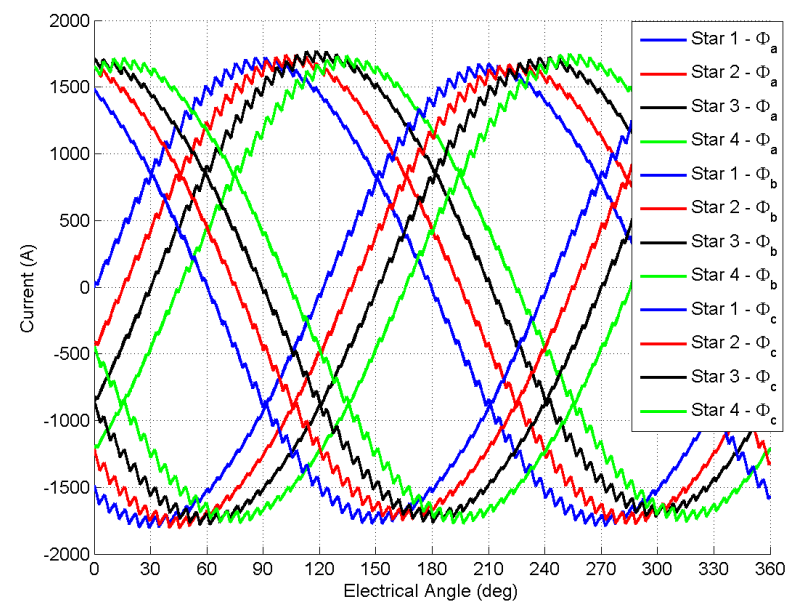

Fig. 8. Phase currents according to the PWM VSI simulation

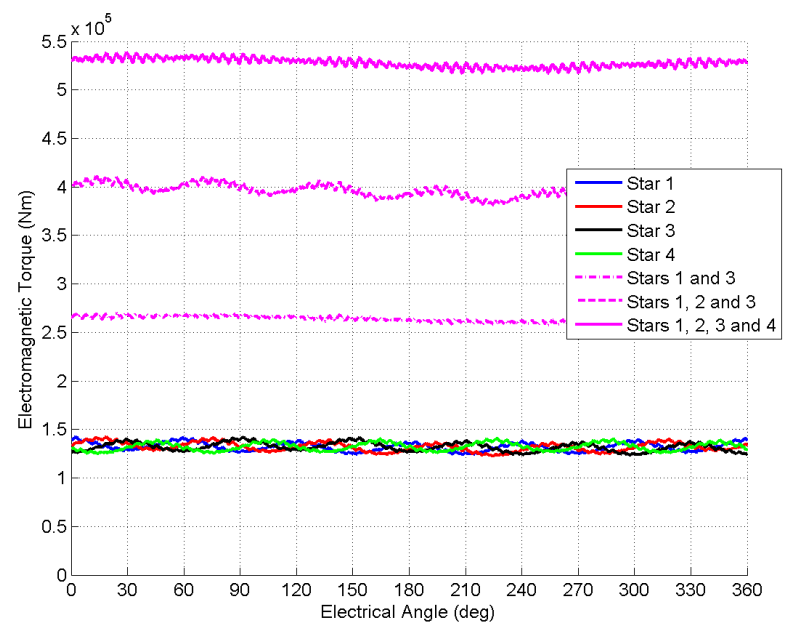

Fig. 9. Maximum electromagnetic torque with PWM current simulation 
TABLE II

PUlSATING TORQUES MAGNitUdeS

\begin{tabular}{|l|l|l|l|}
\hline $\begin{array}{l}\text { Supplied } \\
\text { stars }\end{array}$ & $\begin{array}{l}\text { Average } \\
\text { Torque }\end{array}$ & $\begin{array}{l}\text { Pulsating } \\
\text { Torque } \\
\text { sinus } \\
\text { current) }\end{array}$ & $\begin{array}{l}\text { Pulsating } \\
\text { torque } \\
\text { (PWM } \\
\text { current) }\end{array}$ \\
\hline 1 & $T_{1}=T_{0} / 4$ & $0.09 T_{1}$ & $0.14 T_{1}$ \\
\hline $1 \& 3$ & $T_{13}=T_{0} / 2$ & $\approx 0$ & $0.05 T_{13}$ \\
\hline $1,2 \& 3$ & $T_{123}=3 T_{0} / 4$ & $0.03 T_{123}$ & $0.08 T_{123}$ \\
\hline $1,2,3 \& 4$ & $T_{1234}=T_{0}$ & $\approx 0$ & $0.04 T_{1234}$ \\
\hline
\end{tabular}

windings and separates magnetically and physically the four 3 -phase stars. So the machine is easy to control and a very smooth torque is obtained with a sinusoidal current supply. Furthermore, a very low level of pulsating torque can be attained in faulty mode simply by deconnexion of two nonadjacent stars. The simulation of the PWM VSI confirms this statement. The copper losses and the machine overall volume are also reduced because end-windings are decreased, which is also advantageous for the efficiency. This machine structure is particularly advantageous for the powerfull naval propulsion machine studied in this paper.

Regarding the machine design considered in this paper, the following drawback must be underlined: the proposed fractional-slot multi-star multi-phase winding can generate some magnetomotive force subharmonics that can induce stator mechanical stresses [9] and additionnal rotor losses [10]. So it would be useful to assess their influence. Furthermore the study could be detailled by simulating a phase short-circuit in order to more accurately determine the decoupling level of the three-phase winding and inverter systems. Thus the real fault ability of the machine would be better estimated.

\section{REFERENCES}

[1] P. Letellier, "High power permanent magnet machines for electric propulsion drives," in Proc. of the All Elctric Ship Symposium, Paris, France, 26-27 october 2000, pp. 126-132.

[2] F. Scuiller, E. Semail, J.-F. Charpentier, and P. Letellier, "Multi-criteria based design approach of multiphase permanent magnet low speed synchronous machines," IET Electric Power Applications, vol. 3, no. 2, pp. 102-110, 2009.

[3] S. Brisset, D. Vizireanu, X. Kestelyn, P. Brochet, Y. Milet, and D. Laloy, "Investigation on multi-star structures for large power direct-drive wind generator," Electric Power Components and Systems, vol. 35, pp. 135$152,2007$.

[4] F. Scuiller, J.-F. Charpentier, E. Semail, S. Clénet, and P. Letellier, "Study of unconventional winding configuration of multiphase permanent magnet synchronous machine to improve reliability and torque quality for pod propulsion application." in Proceedings of the 2nd International Conference on Technological in podded propulsion, TPOD2006, Brest, France, 3-5 october 2006.

[5] M. F. Benkhoris, F. Terrien, and J. E. Boucher, "Numerical study of a double star synchronous motor drive for electrical propulsion machine," in Proc. of International Conference on Electric Ship, Istanbul, Turkey, September 1998, pp. 215-220.

[6] F. Scuiller, E. Semail, and J.-F. Charpentier, "General modeling of the windings for multi-phase ac machines. application for the analytical estimation of the mutual stator inductances for smooth air gap machines," Eur. Phys. J. Appl. Phys., vol. 50, no. 3, pp. 1-15, june 2010. [Online]. Available: http://www.epjap.org/articles/epjap/pdf/2010/ 06/ap09444.pdf
[7] M. Lajoie-Mazenc, H. Hector, and R. Carlson, "Procédé d'analyse des champs électrostatiques et magnétostatiques dans les structures planes et de révolution : programme difimedi," in the Proceedings of Compumag, Grenoble, France, September 1978.

[8] B. Backlund, R. Schnell, U. Schlapbach, R. Fischer, and E. Tsyplakov, "Abb application note, applying igbts," ABB Switzerland Ltd, Semiconductors, april 2009, april 2009.

[9] F. Magnussen, D. Svechkarenko, P. Thelin, and C. Sadarangani, "Analysis of a pm machine with concentrated fractional pitch windings," in Proc. of the Nordic Worshop on Power and Industrial Electronics (NORPIE), Trondheim (Norway), 14-15 June 2004.

[10] N. Bianchi and E. Fornasiero, "Impact of $\mathrm{mmf}$ space harmonic on rotor losses in fractional-slot permanent-magnet machines," Energy Conversion, IEEE Transactions on, vol. 24, no. 2, pp. 323 -328, june 2009. 